\title{
APPLICATION OF DIGITAL MICROSCOPE FOR PREDICTION OF SURFACE QUALITY OF CASTINGS
}

\author{
Tomáš OBZINA ${ }^{1}$, Jaroslav BEŇO ${ }^{1}$, Václav MERTA ${ }^{1}$, Petr LICHÝ ${ }^{1}$, Klára DROBÍKOVÁ ${ }^{1}$ \\ ${ }^{1}$ VSB - Technical University of Ostrava, Ostrava, Czech Republic, EU, tomas.obzina@vsb.cz
}

https://doi.org/10.37904/metal.2021.4200

\begin{abstract}
The aim of this work is to determine the possibility of using a digital microscope as a non-contact measurement for the surface quality of cores, and thus to predict the surface quality of pre-casted holes and cavities in manufactured castings. In this study, the test cores were manufactured on a laboratory shooting device with a variable shooting pressure in the range from 0 bar up to 10 bar. The effect of shooting pressure on the mechanical properties of the mixture and the relative porosity of the cores (marked as $m$ ) were studied with the aim to use this data as tool of the casting surface quality prediction. For the research, standardized cores for the determination of transverse strength were prepared. As the core mixture Resin Coated Sand (RCS) technology was used. The technology of non-contact measurement was selected, which was performed on a Keyence VHX 6000 series optical digital microscope, to evaluate the surface quality of the cores (roughness).
\end{abstract}

Keywords: Foundry, casting, surface roughness, cores, RCS

\section{INTRODUCTION}

The surface quality of castings is a hot topic in the foundry industry. Surface quality is closely related to both the functional properties (mechanical properties, corrosion resistance) and the final appearance of the product, which, although usually not affecting the functional quality of the casting, often determines the choice of supplier $[1,2,3]$. The authors [4], who deal with this issue, state that the surface quality of the casting depends on the type of casting technology used. In their research, the surface roughness of the casting was compared on a mould produced by the FDB (furan direct binding/3D mould printing) method and the conventional sand moulding method. The results show the excellent surface quality of the resulting castings, which were cast into moulds made by 3D technology. They also mention the importance of the selected foundry sand fraction. The smaller the size of the sand grains, the better the surface obtained, but at the same time the permeability of the mould is reduced. Non-contact roughness measurement can also be used for roughness measurement $[5,6]$, which is becoming more popular than the conventional method $[7,8]$. The authors [9] compared the roughness of different surfaces of a casting in which cores based on different binder systems (PUCB, furan 3D printed core, RCS) were placed. At the same time, they compared the area roughness (Sa) of the cores and found that the cores made using RCS (resin coated sand) have excellent surface properties.

In this work, the surface quality of the RCS mixture cores produced at different shooting pressure was compared. Comparisons were made both theoretically (determined by relative porosity $\mathrm{m}$ ) and practically using strength characteristics, surface roughness (based on values of arithmetic mean roughness Ra, surface roughness height $\mathrm{Rz}$ ) and area roughness (Sa, Sz) of the cores. Finally, it is shown how the surface quality of the cores can be predicted on the basis of the production parameters.

\section{MATERIALS AND METHOD}

For the purpose of the research, RCS cores were fabricated on a LUT laboratory shooting machine, Morek Multiserw, using a triple core box with a single cavity size of $22.5 \times 22.5 \times 170 \mathrm{~mm}$. The parameters of the 
core production were as follows: core box temperature $280^{\circ} \mathrm{C}$, curing time $120 \mathrm{~s}$, shooting time $2 \mathrm{sec}$. The above parameters were kept constant during core production. The only variable parameter was the shooting pressure of the mixture, which was increased in steps of 2 bar from 0 to 10 bar.

A Keyence VHX 6000 digital microscope equipped with a dual zoom objective with a magnification range of $20 x$ to $2000 x$ was used to compare the surface roughness ( $R a, R z)$ and area roughness ( $\mathrm{Sa}, \mathrm{Sz}$ ) of the cores. The areas on which the measurements were performed are shown in (Figure 1). The start of the measured area was always placed $50 \mathrm{~mm}$ from the bottom edge of the core respectively from the bottom of the core box where the vent screen is located.

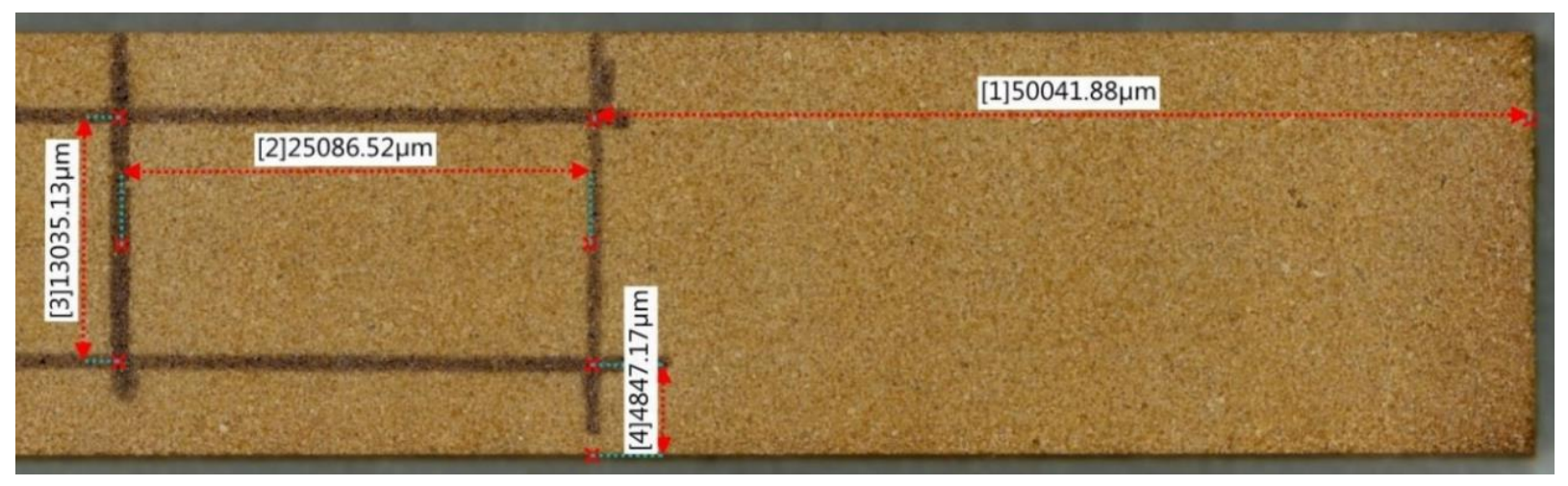

Figure 1 Location of measured areas of cores

The surface roughness ( $\mathrm{Ra}, \mathrm{Rz}$ ) of all cores was measured at 500x magnification using coaxial light. The photo was created using the "stitching" function so that the evaluation length corresponds to $4 \mathrm{~mm}$. The resulting photographed image with a size of $10,375 \times 1,234$ pixels was then used to insert 5 lines from which the roughness data were obtained.

The averages of the taken core roughness values ( $R a$ and $R z$ ) can be found in (Table 3 and Figure 3). The cut-off parameters were chosen as follows: cut-off wavelength $\lambda c=0.8 \mathrm{~mm}$, shortwave filter $\lambda \mathrm{s}=2.5 \mathrm{~mm}$. The measurement was performed in accordance with ISO EN 4288:1998.

Area roughness ( $\mathrm{Sa}$ and $\mathrm{Sz}$ ) were measured on the same core area as in the case of surface roughness (Figure 1), see above. The parameter Sa is like the roughness parameter $\mathrm{Rz}$ which is related to the area. The Sz parameter is defined as "the sum of the largest peak height value and the largest pit depth value within the definition area" according to the standard ISO EN 25178.To evaluate the surface quality of the cores, three values of surface roughness were taken from each core, where the measured/evaluated area was $1 \times 1 \mathrm{~mm}$, see (Table 4). The measurement parameters were selected as follows: filter type $=$ Gaussian, $S$-filter $=5$, $\mathrm{L}$-filter $=0.25$ The measurement was performed according to valid ISO EN 25178 standards.

\section{RESULTS AND DISSCUSION}

Immediately after curing, the middle core was taken to measure the hot transverse strength (within 10 seconds of core production). Cold transverse strength was determined on the remaining cores (60 min after core production). The achieved values of the transverse strengths are captured in (Table 1 and Figure 2). From the given values it can be concluded that the increasing shooting pressure has a positive effect on the transverse strength. The reason is the increase of number of the mutual contact of individual sand grains, resp. formation of a larger number of binder bridges due to a reduction in the degree of freedom of the mixture. However, the values of the transverse strength increase to a value of the shooting pressure of 4 bar, a further increase of the shooting pressure no longer brings an increase in strength, the achieved values of strength are already constant. The reason is probably the achievement of the maximum arrangement of the system, which should be reflected in the lowest value of relative porosity (minimum amount of intergranular spaces). The 
observed decrease in the transverse strength at the shooting pressure of 10 bar is probably due to leakage of the mixture through leaks in the core box, leading to the reduced quality of the core. This effect should also be confirmed by the values of relative porosity $m$ and the values of roughness $\mathrm{Ra}, \mathrm{Rz}$, ( $\mathrm{Sa}, \mathrm{Sz}$ respectively).

Table 1 Influence of shooting pressure on transverse strength of studied cores

\begin{tabular}{|l|l|l|l|l|}
\hline \multirow{2}{*}{$\begin{array}{l}\text { Shooting pressure } \\
\text { (bar) }\end{array}$} & \multicolumn{2}{|l|}{ Cold transverse strength } & \multicolumn{2}{l|}{ Hot transverse strength } \\
\cline { 2 - 5 } & Sample weight $(\mathrm{g})$ & $\sigma(\mathrm{MPa})$ & Sample weight $(\mathrm{g})$ & $\sigma(\mathrm{MPa})$ \\
\hline 0 & 125.39 & 4.21 & 125.46 & 1.83 \\
\hline 2 & 126.81 & 4.32 & 128.94 & 2.76 \\
\hline 4 & 133.43 & 6.77 & 132.19 & 3.19 \\
\hline 6 & 134.03 & 6.76 & 133.85 & 3.08 \\
\hline 8 & 133.96 & 6.83 & 134.10 & 3.67 \\
\hline 10 & 134.04 & 6.66 & 134.20 & 3.17 \\
\hline
\end{tabular}

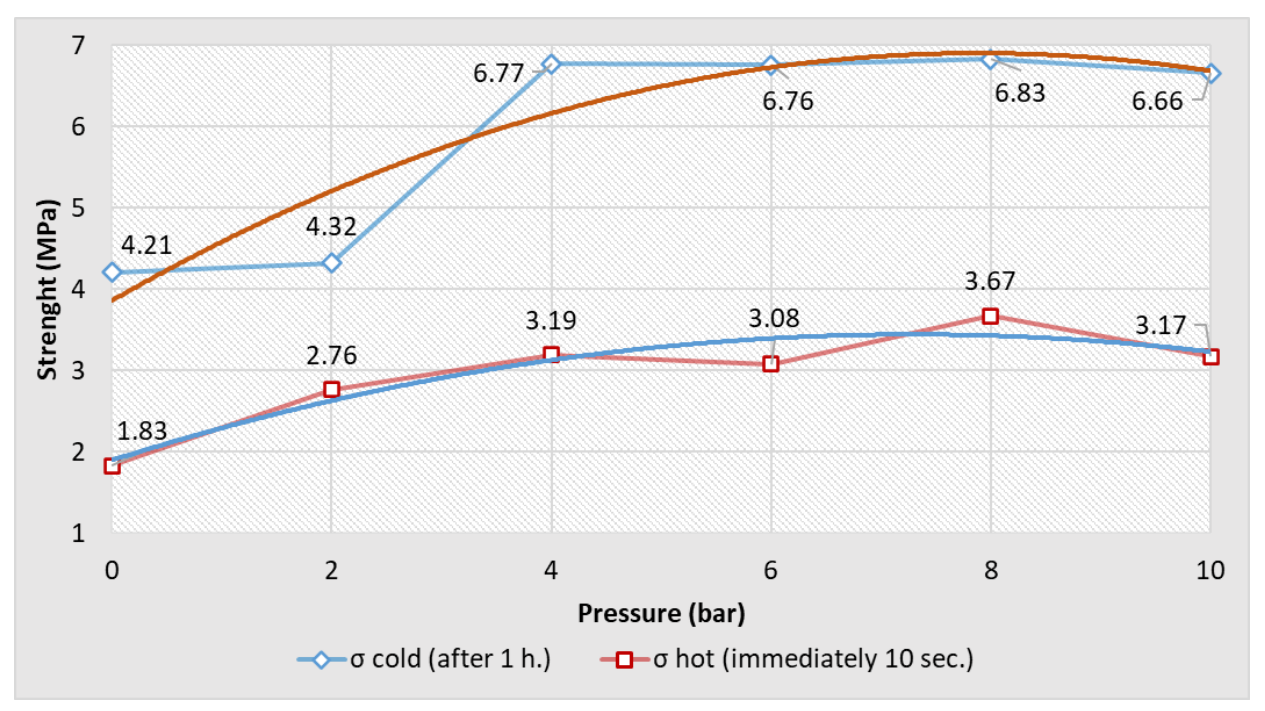

Figure 2 Graphical representation of transverse strength depending on shooting pressure

The achieved values of the mechanical properties of the tested cores also correspond with an increase in the weight of the test specimens up to the values of the shooting pressure of 4 bar. At its higher values, the increase in value is no longer significant, it can be stated that in the range of shooting pressure 6-10 bar, the weight of test specimens is the same. The values of relative porosity $\mathrm{m}$ are closely related to this.

Relative porosity $\mathrm{m}$ was calculated from Equation (1) [11]. The values obtained are given in (Table 2). The determined values of relative porosity $\mathrm{m}$, correlate with the achieved values of the transverse strength. The values show a decrease in the porosity $\mathrm{m}$ with increasing shooting pressure up to a pressure of 4 bar. Subsequently, the porosity values stabilized and were around $40 \%$. It can therefore be determined that higher shooting pressures above 4 bar no longer affect the porosity value. Theoretically, above this pressure, the surface quality should remain the same. However, this is not entirely consistent with the core surface roughness measurements, see below.

$m=\left(\frac{\rho_{1}-\rho_{2}}{\rho_{1}}\right) \cdot 100(\%)$

where:

$\rho_{1}$ - specific weight of sand $\left(\mathrm{kg} \cdot \mathrm{m}^{-3}\right)$

$\rho_{2}$ - density of compacted mixtures $\left(\mathrm{kg} \cdot \mathrm{m}^{-3}\right)$ 
Table 2 Relative porosity values

\begin{tabular}{|l|l|}
\hline Shooting pressure (bar) & Relative porosity (\%) \\
\hline 0 & 44.32 \\
\hline 2 & 43.69 \\
\hline 4 & 40.75 \\
\hline 6 & 40.48 \\
\hline 8 & 40.51 \\
\hline 10 & 40.48 \\
\hline
\end{tabular}

The values of Ra have, as expected, a decreasing course up to the values of the shooting pressure of 6 bar. Higher values of shooting pressures ( 8 and 10 bar) are reflected in a slight increase in roughness. It can be stated that from a pressure of 6 bar the course of roughness $\mathrm{Ra}$ is constant and there is a slight statistical deviation in the measurement or there is a slight blowing of the mixture out of the core. On the contrary, the trend of $R z$ values is manifested by a decrease up to a shooting pressure of 10 bar.

Table 3 Average values of surface roughness of cores ( $R a, R z)$

\begin{tabular}{|l|l|l|l|l|}
\hline Shooting pressure $(\mathrm{bar})$ & $\mathrm{Ra}(\mu \mathrm{m})$ & $\mathrm{Rz}(\mu \mathrm{m})$ & Standard deviation Ra $(\mu \mathrm{m})$ & Standard deviation Rz $(\mu \mathrm{m})$ \\
\hline 0 & 60.69 & 283.94 & 6.74 & 22.24 \\
\hline 2 & 40.39 & 201.58 & 3.80 & 22.27 \\
\hline 4 & 38.88 & 198.76 & 1.14 & 4.36 \\
\hline 6 & 32.78 & 172.08 & 3.43 & 19.70 \\
\hline 8 & 33.59 & 169.75 & 1.96 & 11.92 \\
\hline 10 & 34.03 & 160.78 & 1.86 & 20.60 \\
\hline
\end{tabular}

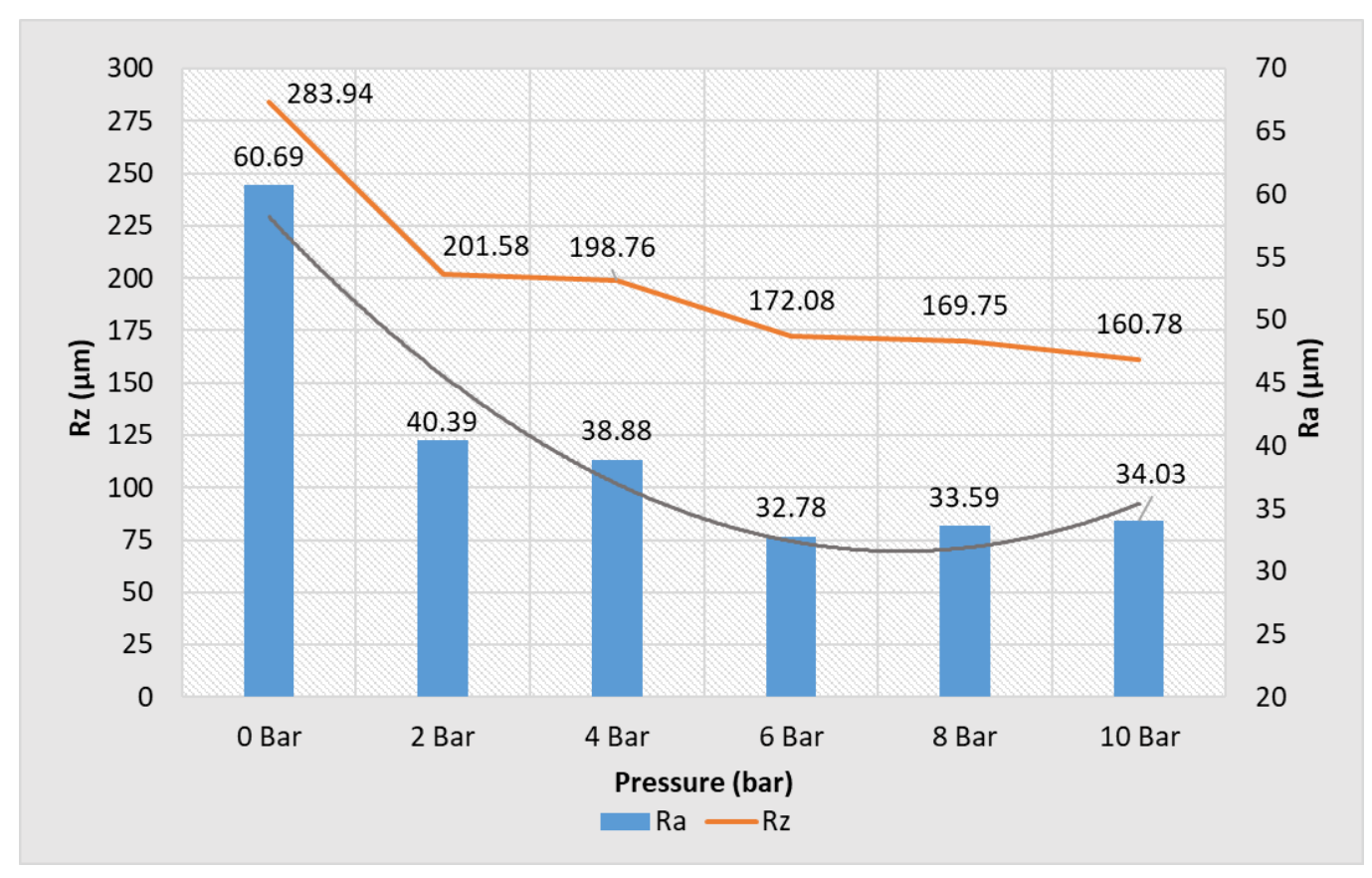

Figure 3 Graphical representation of surface roughness of cores ( $R a, R z)$

Table 4 shows the average values of area roughness Sa and Sz. For better clarity, the measurement values are shown graphically (Figure 4). From the results it can be determined that cores manufactured at the shooting pressure of 0 bar show the highest area roughness (Sa) of all obtained results, as is the case with 
the parameter $\mathrm{Sz}$. If we evaluate the surface quality only by the parameter $\mathrm{Sa}$, the lowest values are reached by the cores shot at 8 bar (respectively 10 bar in case of Sz). From an economic point of view, however, a pressure of 6 bar seems to be the most optimal, as the Sa and Sz parameters reach the second lowest measured values.

Table 4 Average values of area surface roughness of core surfaces (Sa, Sz)

\begin{tabular}{|l|l|l|l|l|}
\hline Shooting pressure $(\mathrm{bar})$ & Sa $(\mu \mathrm{m})$ & Sz $(\mu \mathrm{m})$ & Standard deviation Sa $(\mu \mathrm{m})$ & Standard deviation Sz $(\mu \mathrm{m})$ \\
\hline 0 & 36.20 & 422.81 & 0.70 & 77.47 \\
\hline 2 & 26.75 & 381.51 & 1.10 & 35.00 \\
\hline 4 & 29.06 & 403.63 & 2.49 & 57.14 \\
\hline 6 & 25.81 & 320.9 & 0.72 & 18.58 \\
\hline 8 & 25.25 & 359.35 & 1.99 & 78.66 \\
\hline 10 & 26.00 & 294.09 & 1.27 & 24.04 \\
\hline
\end{tabular}

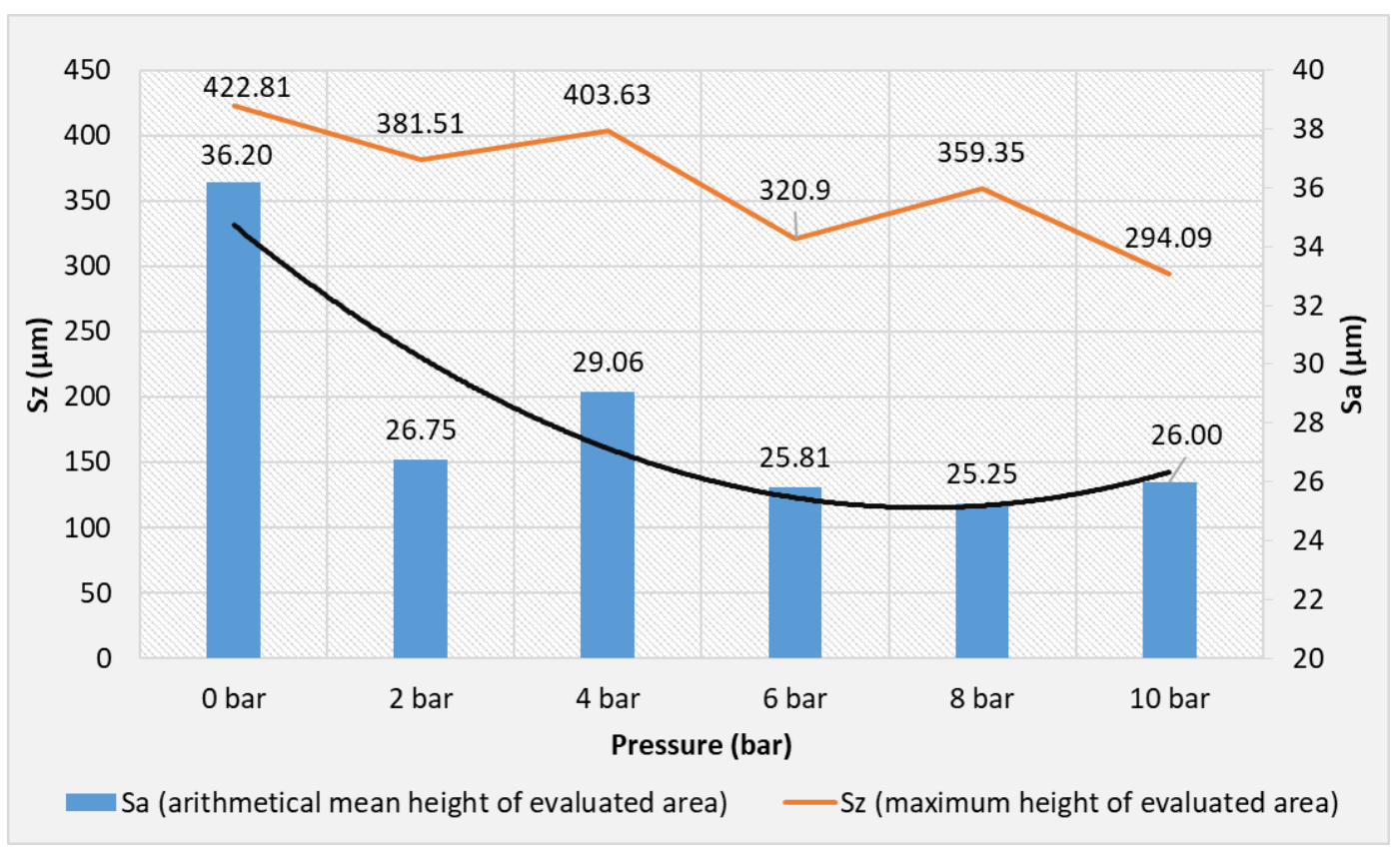

Figure 4 Graphic representation of area roughness of core (Sa, Sz)

\section{CONCLUSION}

The aim of this work is to determine the possibility of using a digital microscope for non-contact measurement of the surface quality of cores, on the basis of which the surface quality of precasted holes and cavities in manufactured castings can be predicted. The surface quality of the cores was subsequently evaluated by determining the core mean arithmetic roughness (Ra); the mean depth roughness (Rz) and, for a comprehensive characterization of the surface quality of the cores, the mean arithmetic height of the area evaluated $(\mathrm{Sa})$ and the maximum height of the area evaluated $(\mathrm{Sz})$. The use of a digital microscope to predict the surface quality of castings by determining core roughness values appears to be advantageous. From the obtained values of the mechanical properties of the cores, respectively the calculated value of the relative porosity, it is evident that the surface quality (roughness) of the cores is in direct dependence with the shooting pressure for the production of the cores in the interval from 0 bar to $4 \mathrm{bar}$. A further increase in injection pressure has no direct effect on the properties of the cores or their roughness. Only at an injection pressure of 10bar it can be stated that this injection pressure is already so high that the surface quality of the cores is reduced, which can have a negative effect on the surface quality of the castings from the cores (precasted cavities). 


\section{ACKNOWLEDGEMENTS}

This work was supported by the Doctoral grant competition VŠB TU-Ostrava, reg. no. CZ.02.2.69/0.0/0.0/19_073/0016945 within the Operational Programme Research, Development and Education, under project DGS/TEAM/2020-037 „Possibilities of influencing the collapsibility of core mixtures for use in technologies for the production of castings from aluminium alloys and magnesium alloys “

\section{REFERENCES}

[1] ASILTÜRKA, İ., ÇUNKAŞ, M. Modeling and prediction of surface roughness in turning operations using artificial neural network and multiple regression method. Expert Systems with Applications. [online]. 2011, vol. 38, Issue 5, pp. 5826-5832. Available from: https://doi.org/10.1016/i.eswa.2010.11.041.

[2] SHRESTHA, R., SIMSIRIWONG, J., SHAMSAEI, N. Fatigue behavior of additive manufactured 316L stainless steel parts: Effects of layer orientation and surface roughness. Additive Manufacturing. [online]. 2019, vol. 28, pp. 23-38. Available from: https://doi.org/10.1016/j.addma.2019.04.011.

[3] GOCKEL, J., SHERIDAN, L., KOERPER, B., WHIP, B. The influence of additive manufacturing processing parameters on surface roughness and fatigue life. International Journal of Fatigue. [online]. 2019, vol. 124, pp. 380-388. Available from: https://doi.org/10.1016/j.ijfatigue.2019.03.025.

[4] HAWALDAR, N., ZHANG, J. A comparative study of fabrication of sand casting mold using additive manufacturing and conventional process. The International Journal of Advanced Manufacturing Technology. [online]. 2018, vol. 97, pp. 1037-1045. Available from: https://doi.org/10.1007/s00170-018-2020-z.

[5] ALAZZAWI, K. M., BEYOGLU, B., HABER, A. R. A study in a tape casting based stereolithography apparatus: Role of layer thickness and casting shear rate. Journal of Manufacturing Processes. [online]. 2021, vol. 64, pp. 1196-1203. Available from: https://doi.org/10.1016/j.jmapro.2021.02.040.

[6] LEKSYCKI, K., KRÓLCZYKB, B. J. Comparative assessment of the surface topography for different optical profilometry techniques after dry turning of Ti6Al4V titanium alloy. Measurement. [online]. 2021, vol. 169, p. 11. ISSN 0263-2241. Available from: https://doi.org/10.1016/i.measurement.2020.108378.

[7] PANTHANGI, K. R., RAO K. S., BABU B. S. Optimization of surface roughness in turning of LM9 aluminum casting alloy. Materials Today: Proceedings. [online]. 2021, vol. 41, part 5, pp. 1164-1168. Available from: https://doi.org/10.1016/j.matpr.2020.09.483.

[8] SINGH, J., SINGH, R., SINGH, H. Surface roughness prediction using Buckingham's Pi-theorem for SS-316L hip implant prepared as rapid investment casting. Materials Today: Proceedings. [online]. 2018, vol. 5, issue 9, part 3, pp. 18080-18088. Available from: https://doi.org/10.1016/j.matpr.2018.06.142.

[9] TUTTLE, R., RAMRATTAN, S., WELLS, L. As-Cast Surface Characterization for Steel Using Disk-Shaped Chemically Bonded Sand Specimens. Inter Metalcast. [online]. 2021, vol. 15, pp. 382-390. Available from: https://doi.org/10.1007/s40962-020-00520-4.

[10] JELÍNEK, P. Pojivové soustavy slévárenských formovacích směsí. Ostrava: 2004. 